\title{
Keefektifan Model Course Review Horay (CRH) Berbantu Media Kartu Pecahan Terhadap Hasil Belajar Matematika
}

\author{
Uswatun Khasanah ${ }^{1}$, Rasiman $^{2}$, Arfilia Wijayanti $^{3}$ \\ 1,2,3 Jurusan Pgsd, Universitas Pgri, Semarang, \\ e-mail: uswatun@gmail.com, rasiman@gmail.com, arilia@yahoo.co.id3
}

\begin{abstract}
ABSTRAK
Latar belakang yang mendorong penelitian ini adalah (1) Model pembelajaran yang digunakan guru masih konvensional, (2) Siswa cenderung senang bermain dan bercerita dengan temannya saat pembelajaran berlangsung, dan (3) Rendahnya hasil belajar matematika siswa kelas V. Tujuan penelitian ini adalah untuk mengetahui ada keefektifan model pembelajaran Course Review Horay $(\mathrm{CRH})$ berbantu media kartu pecahan terhadap hasil belajar matematika kelas $\mathrm{V}$ SD Negeri Sidokumpul. Jenis penelitian ini adalah kuantitatif. Populasi penelitian ini adalah siswa-siswa SD Negeri Sidokumpul. Adapun sampel penelitian ini adalah kelas $V$ yang terdiri dari 18 siswa. Desain penelitian menggunakan true experimental design, bentuk yang dipilih yaitu One Group Pretest dan Posttest Design. Alat pengumpulan data berupa tesintelegensi. Hasil analisis uji-t didapat Ho ditolak. Jadi dapat disimpulkan bahwa Hasil belajar siswa yang menempuh postest ketika mendapatkan model pembelajaran course review horay berbantu kartu pecahan lebih baik daripada hasil belajar siswa ketika menempuh pretest sebelum mendapatkan model pembelajaran tersebut. Perolehan ketuntasan belajar individu pada postest adalah tuntas 14 dari 18 siswa dan ketuntasan belajar kelompok mencapai $77,8 \%$. Oleh karena itu dapat disimpulkan bahwa adanya keefektifan model pembelajaran Course Review Horay berbantu media kartu pecahan terhadap hasil belajar matematika kelas V SDN Sidokumpul.
\end{abstract}

Kata kunci: keefektifan, Course Review Horay, Kartu pecahan, matematika

\section{ABSTRACT}

The background that drives this research are (1) The learning model used by the teacher is still conventional, (2) Students tend to enjoy playing and telling stories with friends when learning takes place, and (3) The low mathematics learning outcomes of class $\mathrm{V}$ students. knowing the effectiveness of the Course Review Horay (CRH) learning model aided by fraction card media on the results of the fifth grade mathematics learning at SD Sidokumpul. This type of research is quantitative. The population of this study were students of Sidokumpul Elementary School. The sample of this study is class $V$ which consists of 18 students. The research design uses true experimental design, the form chosen is One Group Pretest and Posttest Design. The data collection tool is in the form of intelligence tests. The results of the t-test analysis found that Ho was rejected. So it can be concluded that the learning outcomes of students who take the posture when getting a learning model for a horay review course assisted by a fraction card are better than student learning outcomes when taking a pretest before getting the learning model. The acquisition of individual learning completeness in the post was completed 14 out of 18 students and group learning completeness reached $77.8 \%$. Therefore, it can be concluded that the effectiveness of the Course Review Horay learning model is aided by fraction card media on the results of the fifth grade mathematics learning at Sidokumpul Elementary School.

Keywords: effectiveness, Course Review Horay, Fraction Cards, mathematics 


\section{Pendahuluan}

Undang- Undang Sistem Pendidikan Nasional (UUSPN) No. 20 Tahun 2003 Bab 1, pasal 1 yang berbunyi:" pendidikan adalah usaha sadar dan terencana untuk mewujudkan suasana belajar dan proses pembelajaran agar peserta didik secara aktif dapat mengembangkan potensi diri, kepribadian, kecerdasan, akhlak mulia, serta ketrampilan yang diperlukan dirinya, masyarakat, bangsa dan Negara". Menurut (Nahar,Sulistyaningsih \& Purnomo,2016 :49) Salah satu aspek yang banyak sorotan dari masyarakat adalah pendidikan. Karena aspek tersebut merupakan faktor penentu kemajuan suatu bangsa.

Berdasarkan penjelasan di atas dapat diketahui bahwa generasi muda atau calon penerus bangsa dalam proses belajar diharapkan mampu mengembangkan potensi diri, kepribadian, kecerdasan, akhlak mulia serta memiliki ketrampilan untuk dirinya, masyarakat, bangsa dan Negara sebagaimana yang tertuang dalam UUSPN No. 20 Tahun 2003.

Era globalisasi saat ini, manusia dituntut untuk mengembangkan kemampuan IPTEK dan mampu memenuhi kebutuhan masyarakat. Begitu pula yang terjadi pada pembelajaran Matematika di sekolah dasar. Dalam hal ini guru dituntut untuk bersikap profesional, yang mana guru harus memiliki kemampuan penguasaan materi pembelajaran secara luas dan mendalam serta diharapkan mampu membimbing peserta didik untuk memenuhi standar kompetensi yang ditetapkan. Seperti yang tertuang dalam Standar Nasional Pendidikan (SNP, penjelasan Pasal 28 ayat 3 butir c) yang menyatakan bahwa guru harus memiliki pengetahuan yang luas berkenaan dengan bidang studi yang akan diajarkan serta penguasaan pembelajaran yang mengikuti pendekatan ilmiah dalam arti memiliki pengetahuan konsep teoritis, mampu memilih model, strategi, dan metode yang tepat serta mampu menerapkannya dalam kegiatan pembelajaran.

Dalam upaya meningkatkan hasil belajar siswa dalam pecahan sederhana, maka diperlukan media pembelajaran yang sesuai. Salah satu alternatif media pembelajaran yang dapat digunakan oleh guru adalah kartu pecahan. Menurut Shamsudin (2002: 62) Kertu pecahan digunakan sebagai alat peraga yang memuat gambar pecahan suatu benda dengan pecahan yang sesuai.

\section{Metode}

Penelitian ini dilaksanakan di SD Negeri Sidokumpul pada semester I Tahun Ajaran 2018/2019. penelitian ini menggunakan dua variabel yaitu variabel bebas dan variabel terikat. Dalam penelitian ini menggunakan variabel bebas yaitu model pembelajaran Course Review Horay $(\mathrm{CRH})$ berbantu media Kartu Pecahan di SD Negeri Sidokumpul dan yang menjadi variabel terikat adalah hasil belajar siswa kelas V SD Negeri Sidokumpul.

Metode yang digunakan adalah kuantitatif dengan Desain true experimental desaign bentuk True Experimen Design yang digunakan adalah One Group Pretest dan Posttest Design. Dengan demikian hasil perlakuan dapat diketahui lebih akurat, karena membandingkan dengan keadaan sebelum diberi perlakuan.

Teknik pengumpulan data pada penelitian ini adalah dengan menggunakan tes. Instrumen tes (pretest-postest) yang berupa essay, observasi dan dokumentasi yang dilakukan dalam kegiatan pembelajaran dikelas. Nilai pretest postest dinyatakan tuntas jika nilai tersebut sudah memenuhi KKM. Adapun kriteria ketuntasan minimal (KKM) yaitu 65. perhitungan pretest dan postest setelah diberi perlakuan.

\section{Hasil dan Pembahasan}

Pada penelitian ini, peneliti menggunakan dua kelas yaitu kelas eksperimen dan kelas kontrol. Pada kelas eksperimen yang di berikan perlakuan pemebelajaran dengan menggunakan model pemebelajaran Coure Review Horay $(\mathrm{CRH})$ berbantu media Kartu Pecahan, sedangkan kelas kontrol yaitu yang diberikan pembelajran konvesional atau dengan menggukan penjelasan dari guru. 
Tabel 1. Nilai Pretest dan postest Hasil Belajar Siswa

\begin{tabular}{lllllll}
\hline Tes & Terendah & Tertinggi & Rata-rata & Belum tuntas & Tuntas & Peningkatan \\
\hline Pretest & 42 & 70 & 56,11 & 13 & 5 & $\mathbf{7 , 5 \%}$ \\
Postest & 20 & 95 & 63,61 & 4 & 14 & \\
\hline
\end{tabular}

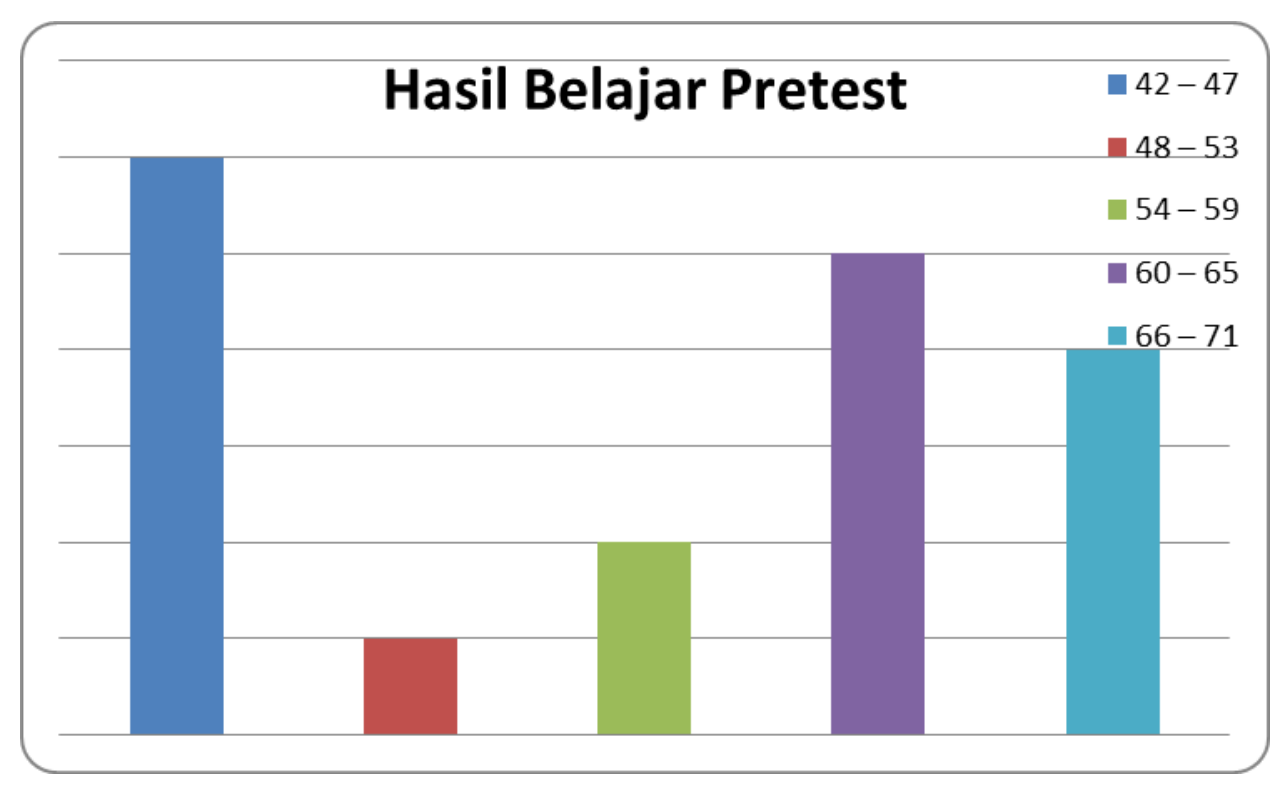

Gambar 1. Diagram Frekuensi Hasil Belajar Pretest

Berdasarkan diagram histogram dapat diketahui bahwa frekuensi hasil belajar pretest memperoleh nilai $42-47$ sebanyak 6 siswa atau $33,3 \%$, nilai 48 - 53 sebanyak 1 siswa atau 5,6\%, nilai 54 - 59 sebanyak 2 siswa atau $11,1 \%$, nilai $60-65$ sebanyak 5 siswa atau $27,8 \%$, dan nilai 66 - 71 sebanyak 4 siswa atau $22,2 \%$.

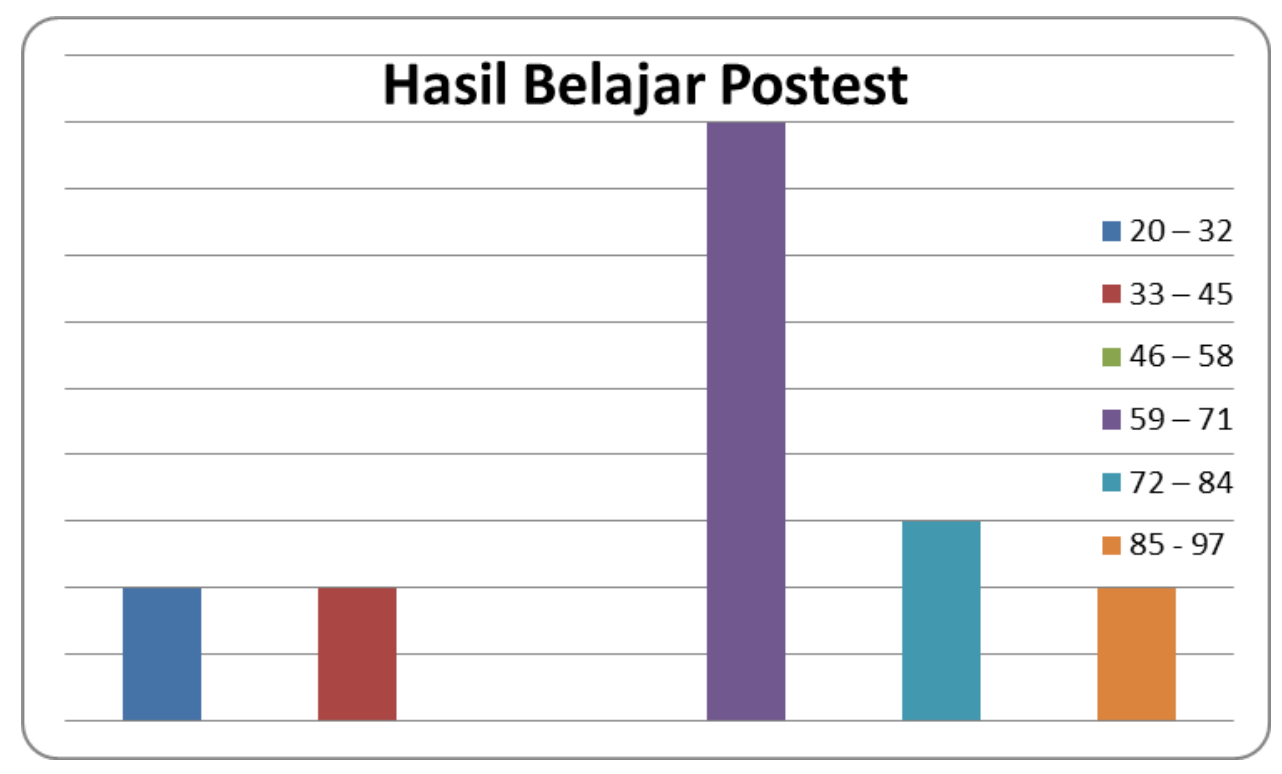

Gambar 2. Diagram Frekuensi Hasil Belajar Posttest

Berdasarkan diagram histogram dapat diketahui bahwa frekuensi hasil belajar postest memperoleh nilai 20 - 32 sebanyak 2 siswa atau $11,1 \%$, nilai $33-45$ sebanyak 2 siswa atau $11,1 \%$, nilai 46 - 58 sebanyak 0 siswa atau $0 \%$, nilai $59-71$ sebanyak 9 
siswa atau $50 \%$, nilai 72 -84 sebanyak 3 siswa atau $16,7 \%$, dan nilai 85 - 97 sebanyak 2 siswa atau $11,1 \%$.

Uji normalitas awal diambil dari data nilai pretest siswa kelas V. Untuk menganalisis normalitas data menggunakan uji Liliefors pada taraf signifikansi 5\% dan dikatakan normal apabila L0< Ltabel. Dari perhitungan diperoleh hasil sebagai berikut:

Uji normalitas nilai pretest siswa kelas $\mathrm{V}$ dengan $\mathrm{n}=18$ dan $=5 \%$ maka hasil perhitungan diperoleh $\mathrm{LO}=0,1755$ dan Ltabel $=0,2088$. Dari hasil tersebut karena harga L0 $<$ Ltabel yaitu 0,1755 < 0,2088 maka kelas yang telah menempuh pretest berasal dari populasi yang berdistribusi normal.

Uji normalitas akhir diambil dari data nilai postest siswa kelas V. Untuk menganalisis normalitas data menggunakan uji Liliefors pada taraf signifikansi 5\% dan dikatakan normal apabila L0 < Ltabel. Dari perhitungan diperoleh hasil sebagai berikut:

Uji normalitas nilai postest siswa kelas $\mathrm{V}$ dengan $\mathrm{n}=18$ dan $=5 \%$ maka hasil perhitungan diperoleh $L 0=0,1177$ dan Ltabel $=0,2088$. Dari hasil tersebut karena harga L0 $<$ Ltabel yaitu 0,1177 < 0,2088 maka kelas yang menempuh postest berasal dari populasi yang berdistribusi normal.

Untuk hipotesis penelitian uji t satu pihak yaitu antara yang mendapat pembelajaran yang menggunakan model Course Review Horay dengan sebelum mendapatkan model Course Review Horay di SD Negeri Sidokumpul, Guntur, Demak didapatkan thitung = 5,86. Untuk selanjutnya thitung yang sudah didapat dikonsultasikan dengan ttabel, dengan $5 \%$ dan $\mathrm{dk}=\mathrm{n}-2$.

Karena hipotesis penelitian thitung $>$ ttabel yaitu 5,86 $>1,74$ maka kesimpulannya adalah hasil belajar postest lebih baik daripada hasil belajar pretest dengan model pembelajaran Course Review Horay berbantu media kartu pecahan pada materi matematika kelas V SDN Sidokumpul.

\section{Uji Ketuntasan Belajar.}

Dari hasil data pretest didapatkan jumlah siswa yang tuntas berjumlah 4 siswa yang mendapatkan nilai diatas 65 . Kemudian jumlah siswa yang tidak tuntas berjumlah 14 siswa yang mendapatkan nilai dibawah 65 . Sedangkan hasil data postest didapatkan jumlah siswa yang tuntas berjumlah 14 siswa yang mendapatkan nilai diatas 65. Kemudian jumlah siswa yang tidak tuntas berjumlah 4 siswa yang mendapatkan nilai dibawah 65 . Sehingga dapat dilihat bahwa siswa yang tuntas ketika telah mendapatkan model pembelajaran Course Review Horay lebih tinggi daripada sebelum mendapatkan model pembelajaran tersebut.

Ketuntasan Belajar Klasikal

Dengan pencapaian hasil pretest siswa yang tuntas ada 4 siswa dari 18 siswa maka persentase ketuntasan ketika menempuh pretest $22,2 \%$. Sedangkan pencapaian hasil postest siswa yang tuntas adalah 14 siswa dari 18 siswa maka persentase ketuntasan setelah mendapatkan model pembelajaran Course Review Horay sebesar $77,8 \%$. Oleh karena itu, hasil postest telah mencapai lebih dari $65 \%$.

Berdasarkan hasil analisis yang telah dilakukan pada data nilai pretest dan postest kelas V SD Negeri Sidokumpul dikatakan bahwa hasil belajar siswa berdistribusi normal. Hasil uji-t satu pihak dimana thitung yang sudah didapat dikonsultasikan dengan ttabel, dengan $5 \%$ dan $\mathrm{dk}=\mathrm{n}-2$, didapatkan hasil thitung $>$ ttabel yaitu 5,86 >1,74 maka kesimpulannya adalah hasil belajar siswa yang menempuh postest lebih baik daripada ketika menempuh pretest setelah menggunakan model pembelajaran course review horay berbantu media kartu pecahan pada pelajaran matematika kelas V SDN Sidokumpul. Kemudian ketuntasan belajar individu siswa yang menempuh postest lebih tinggi dari pada siswa yang menempuh postest dengan pencapai 14 siswa untuk postest dan 4 siswa untuk pretest. Selanjutnya ketuntasan belajar klasikal didapat hasil belajar siswa setelah menempuh postest memiliki persentase ketuntasan $77,8 \%$, hal ini pencapaian ketuntasan klasikal setelah menempuh postest lebih dari 65\%. Sedangkan siswa yang menempuh pretest ketuntasan belajar klasikal mendapat persentase $22,2 \%$.

Berdasarkan hasil penelitian, semua permasalahan yang melatar belakangi pelaksanaan penelitian ini dapat terjawab dan terpecahkan dengan penjelasan pembahasan 
diatas. Sehingga hipotesis dan tujuan penelitian dapat tercapai, yaitu adanya keefektifan model pembelajaran Course Review Horay berbantu media kartu pecahan terhadap hasil belajar matematika kelas V SDN Sidokumpul.

\section{Simpulan dan Saran}

Berdasarkan hasil analisis data penelitian, Dari hasil penelitian uji t satu pihak menunjukan bahwa melalui uji $t$ diperoleh thitung $>$ ttabel yaitu 5,86 > 1,74 maka kesimpulannya adalah hasil belajar siswa ketika menempuh postest ketika mendapatkan model pembelajaran Course Review Horay berbantu media kartu pecahan lebih baik daripada ketika menempuh pretest sebelum mendapatkan model pembelajaran tersebut.

Ketuntasan belajar individu kelas eksperimen telah mencapai rata-rata nilai lebih dari 65 dengan 14 dari 18 siswa tuntas secara individu. Selanjutnya berdasarkan ketuntasan belajar klasikal persentase jumlah siswa yang tuntas secara klasikal pada siswa yang menempuh postest telah melampaui $65 \%$ dengan persentase ketuntasan siswa mencapai $77,8 \%$ dari 18 siswa.

Berdasarkan hasil penelitian, maka saran yang dapat diajukan adalah sebagai berikut:

1. Bagi Guru

Saran untuk guru yaitu pembelajaran dengan menggunakan model pembelajaran Course Review Horay berbantu media kartu pecahan dapat dilaksanakan dalam proses belajar mengajar sebagai variasi mengajar sehingga tidak monoton dan menciptakan kreatifitas pada siswa serta percaya diri dalam pembelajaran. Model pembelajaran Course Review Horay berbantu media kartu pecahan sudah terbukti dapat meningkatkan hasil belajar siswa.

2. Bagi pembaca

Model pembelajaran Course Review Horay berbantu media kartu pecahan direkomendasikan penulis untuk terus dikembangkan agar siswa tertarik dan termotivasi. Khususnya untuk mengajar mata pelajaran Matematika yang memerlukan variasi mengajar yang bukan hanya sekedar ceramah. Model pembelajaran Course Review Horay berbantu media kartu pecahan dapat dilakukan untuk menciptakan pembelajaran yang bermakna dan menyenangkan serta membuat siswa lebih memahami materi yang disampaikan.

\section{Daftar Pustaka}

Anitah. (2008). Strategi Pembelajaran di SD. Jakarta: Universitas Terbuka.

Ardiani, dkk. Keefektifan pembelajaran $\mathrm{CRH}$ berbantuan Kartu Masalah dalam peningkatan Kemampuan Pemecahan Masalah dan disposisi Matematik Siswa SMP Kelas VII. Diss. Universitas Negerri Semarang, 2015.

Arikunto, Suharsimi.2013.Prosedur Penelitian Suatu Pendekatan Praktik.Jakarta: Rineka Cipta.

Hamalik. (1991). Strategi Belajar Mengajar. Bandung: CV Sinar Baru.

Huda, M. (2015). Cooperatif Learning Metode, Teknik, Struktur dan Model Penerapan. Yogyakarta: Pustaka Pelajar.

Huda, M. (2014). Model-model Pengajaran dan Pembelajaran. Yogyakarta: Pustaka Pelajar.

Mahani, E. P., dkk. "Keefektifan Model Course review Horay Berbantuan Powerpoint pada Kemampuan Pemecahan masalah Siswa". Unnes Journal Of Mathematic Education $2.3(2013)$

izki, R. A., Triyono, \& Suhartono. (2016). PENERAPAN MODEL COURSE REVIEW HORAY DENGAN MEDIA KONKRET. kalam Cendekia, vol. 4 No. 3, 360

Sardiman. (2012). Interaksi dan Motivasi Belajar Mengajar. Jakarta: Raja Grafindo Persada. 
Shamsudin (Rusmiyati 2018). Kamus Matematika Bergambar untuk Sekolah Dasar.Jakarta: Grasindo

Shoimin, A. (2014). 68 Model Pembelajaran Inovatif Dalam Kurikulum 2013. Yogyakarta: ArRuzz Media.

Slameto. (2010). Belajar dan Faktor-faktor yang Mempengaruhinya. Jakarta: PT. Rineka Cipta.

Sudjana. 2005. Metode Statistika. Bandung: Tarsito

Sugiyono. 2013. Metode Penelitian Pendidikan. Bandung: Alfabeta.

Suprijono. A. 2009. Cooperative Learning Teori dan Aplikasi Paikem. Yogyakarta. Pustaka Pelajar.

Suprijono. A. 2011. Model-Model Pembelajaran. Jakarta: Gramedia Pustaka Jaya.

Suryani, Asish, Maulana, and Julia. "pengaruh Pendekatan Course Review horay (CRH) Terhadap PemahamanMatematis dan Motivasi Belajar matematika Siswa Sekolah dasar Pada materi penjumlahan dan pengurangan Bilangan Bulat". Jurnal Pena IImiah 1.1 (2016): 81-90.

Yanthi, kadek Novita. Pengaruh Model Course review horay Berbasis Media audio Visual Terhadap Penguuasaan Kompetensi Pengetahuan IPA Siswa Kelas IV Sd Gugus VIII Mengwi Tahun Ajaran 2016/2017. Mimbar PGSD Undiksha, 2017, 5.2. 